\title{
Numerical Study on Frequency Limitation of Sensing Signal for Maglev Rotor Displacement
}

\author{
Te-Jung Chen, ${ }^{1}$ Cheng-Chi Wang, ${ }^{2}$ and Rong-Mao Lee ${ }^{1 *}$ \\ ${ }^{1}$ Department of Intelligent Robotics, National Pingtung University, \\ No. 4-18, Minsheng Rd., Pingtung City, Pingtung County 90003, Taiwan \\ ${ }^{2}$ Graduate Institute of Precision Manufacturing, National Chin-Yi University of Technology, \\ No. 57, Sec. 2, Zhongshan Rd., Taiping Dist., Taichung City 41170, Taiwan
}

(Received July 12, 2020; accepted October 8, 2020)

Keywords: active magnetic bearing, self-sensing, numerical analysis, signal injection, sensorless

A simplified electromagnetic analysis procedure was introduced in this work to investigate the sensorless method of high-frequency injection for the displacement of a maglev rotor. Since the 3D model of electromagnets and the spindle, and the external circuits were all loaded into a single finite-element analysis (FEA) platform, the accuracy of simulation results can be significantly improved. Twenty cases were designed and considered to study the influence of the signal amplitude and frequency on the sensing performance. In addition, preliminary discussions regarding the frequency ranges of the sensing signal, the influence of the control command on the sensing signal, and the detection speed of the spindle displacement are included.

\section{Introduction}

An active magnetic bearing (AMB) is a type of bearing without mechanical contact. For the purpose of achieving a satisfactory reliability of AMB operation, accurate and real-time information of the rotor position is required. Displacement sensors employed in an AMB can be any of the following types: eddy current, inductive, capacitive, optical, Hall element, ultrasonic, and laser. ${ }^{(1)}$ With the aim of reducing the structural complexity and manufacturing cost of AMBs, a variety of self-sensing methods, in which the rotor displacement is estimated from the electrical responses of electromagnets, have been studied. Methods to determine the rotor displacement without a physical sensor can be divided into two categories, as depicted in Fig. 1. ${ }^{(2)}$ The observer-based principle is to estimate the rotor displacement in terms of voltages and currents of the AMB. However, modulation-based approaches were proposed to replace observer-based methods owing to their improved robustness. ${ }^{(3-5)}$ The pulse-widthmodulation (PWM) ripple-based approach was introduced by Okada and Matsushita ${ }^{(6)}$ and Noh. ${ }^{(7)}$ The driving power of an AMB is related to the coil inductance, and the rotor movement results in the variation of the carrier components of the coil current. When an AMB is driven by a PWM amplifier, the rotor displacement can be estimated by using a resonant circuit and *Corresponding author: e-mail: maxmou@mail.nptu.edu.tw https://doi.org/10.18494/SAM.2020.3102 


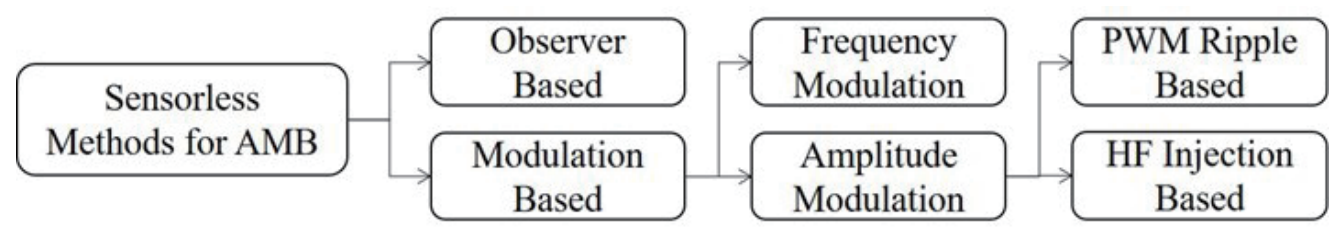

Fig. 1. Classification of sensorless methods to estimate rotor displacement of AMB.

a low-pass filter. "HF Injection" in Fig. 1 refers to injecting a high-frequency voltage into the electromagnet. The relationship between the rotor position deviation and the variation of the injected signal can also be derived.

Yoshida et al. proposed a self-sensing method using a PWM amplifier with dual DC sources. $^{(8)}$ This amplifier can supply a control current and a bias current simultaneously, where the bias current is used to measure the deviation of the rotor position. The proposed method was verified by a five-axis AMB at a rotor speed of $45000 \mathrm{~min}^{-1}$. A self-sensing method with zero-bias current was introduced by Kato et al. ${ }^{(9)}$ A series resonance circuit was inserted to measure the electrical response of PWM-driven electromagnets. The resonance circuit supplied carrier signals to both the opposing electromagnets to provide differential position detection. Tang et al. proposed a signal demodulation process to reduce the complexity of hardware. ${ }^{(10)} \mathrm{A}$ mathematical model for the relationship between rotor displacement, current ripple, and duty cycle was prepared in advance. Then individual duty cycles of the AMB driving signal were measured instead of filtering the coil voltage signal. Since the filter results in a low stability margin, a direct current measurement approach was reported by Niemann et al. ${ }^{(11)}$ A novel power amplifier switching method was employed to measure the current ripple directly to obtain the duty-cycle rotor position. As the PWM switching frequency is generally very high, the update of the rotor displacement estimation at each switching cycle may be difficult. ${ }^{(12,13)}$ A method of estimating rotor displacement to address the above problem was proposed in $2020 .^{(14)}$ Two types of direct current estimator were introduced to analyze the current gradient information and reduce the overhead time of the estimation simultaneously.

The principle of the HF-injection-based method is similar to that of the inductive displacement sensor. A high-frequency signal is injected into the coil and the induced voltage can be detected to estimate the rotor displacement. Park et al. proposed a phase modulation algorithm based on the HF injection method. ${ }^{(15)}$ Currents with a phase difference were injected into opposite electromagnets of an AMB to estimate the shaft displacement. HF-injection-based approaches for the rotor position or speed estimation of a permanent magnet synchronous motor were also reported. ${ }^{(16-18)}$ Sensorless methods for detecting AMB rotor displacement are based on the dynamics of the magnetic field and the inductive reactance of AMB coils. Since the variations of the magnetic field and the coil inductive reactance are both highly nonlinear, a simple numerical analysis procedure was introduced in this work for the preliminary analysis of a sensorless AMB. The HF injection method was employed as an analysis object owing to its adjustability of the signal strength and frequency. According to the theory of the HF injection method, the injected signal frequency should be sufficiently high to achieve a satisfactory 
performance and avoid interfering with the AMB control signal simultaneously. However, the inductive reactance of the coil is proportional to the injected signal frequency. Here, a preliminary study on the performance of the HF injection method against signal frequency using the proposed analysis procedure is reported.

\section{Simplified Numerical Analysis Procedure}

Since the variation of the magnetic field is nonlinear and complex, establishing a mathematical model to fulfill the practical AMB operation is challenging. A pure numerical analysis method without the derivation of the mathematical model is introduced in this paper. The analysis procedure is depicted in Fig. 2. The AMB structure is constructed with the aid of SolidWorks software. The 3D AMB model is loaded into the ANSYS finite element analysis (FEA) package. Before carrying out simulations, the electrical supplies have to be defined under the ANSYS Simplorer multidomain platform. Both the electromechanical and electromagnetic analyses of an AMB can be accomplished in a single task.

\subsection{Principle of $\mathrm{HF}$ injection method}

The magnetic flux linking by an electromagnet is defined as follows:

$$
\psi=N \phi
$$

where $\psi$ is the magnetic flux linking, $N$ is the number of coil turns of the electromagnet, and $\phi$ is the magnetic flux induced by the electromagnet. The reluctance of the iron core of the electromagnet is usually negligible. The induced magnetic flux $\phi$ can be defined as

$$
\phi=\frac{N i}{2 R_{\text {air }}}=\frac{N i \mu_{0} A_{g}}{2 d}
$$

where $R_{\text {air }}$ is the reluctance of the air gap between the rotor and electromagnet, $i$ is the coil current, $\mu_{0}$ is the magnetic permeability of air, $A_{g}$ is the cross-sectional area of the magnetic pole perpendicular to the magnetic field, and $d$ is the length of the air gap. Using Eqs. (1) and (2), the electromagnet inductance $L$ can be represented as

$$
L=\frac{\partial \psi}{\partial i}=\frac{N^{2} \mu_{0} A_{g}}{2 d}
$$

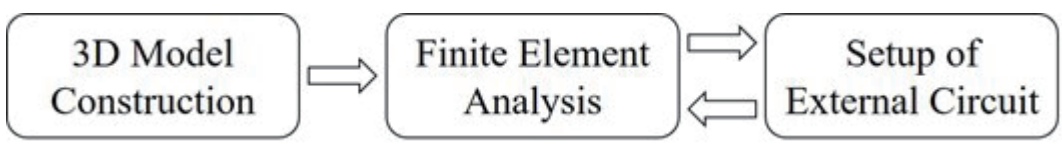

Fig. 2. Proposed analysis procedure for sensorless methods. 
The electromagnet inductance is inversely proportional to the length of the air gap. To measure the variation of the inductance, a high-frequency signal of a constant amplitude can be injected into the coil. The amplitude of the sensing signal should be sufficiently low to maintain the AMB performance. If a high-frequency sine wave signal $V \sin \omega t$ is injected into the coil, the induced peak current $I_{\max }$ can be given as

$$
I_{\max }=\frac{V}{\omega L},
$$

where $V$ is the peak voltage of the sensing signal and $\omega$ is the signal frequency. As a result, the length of the air gap can be estimated by measuring the peak value of the high-frequency component.

\subsection{AMB model}

An embedded cylindrical-array magnetic actuator (ECAMA) is employed in this work. The configuration of the ECAMA is shown in Fig. $3 .^{(19)}$ There are two pairs of electromagnets, one aligned with the $x$-axis and one aligned with the $y$-axis. The direction of magnetic flux is controlled by the coil current, and the magnetic flux around the spindle is guided by a silicon steel layer (the outer layer of the spindle). For simplicity in the following discussion, only one pair of electromagnets is loaded into the FEA platform.

\section{Case Design for HF Injection Analysis}

The model of one pair of electromagnets and the spindle is shown in Fig. 4(a). The two coils are referred to as windings 1 and 2. Each electromagnet is composed of two magnetic poles, one winding, and a silicon steel core (surrounded by the winding). The external circuit for AMB driving and sensing is illustrated in Fig. 4(b). The control current source is the driving

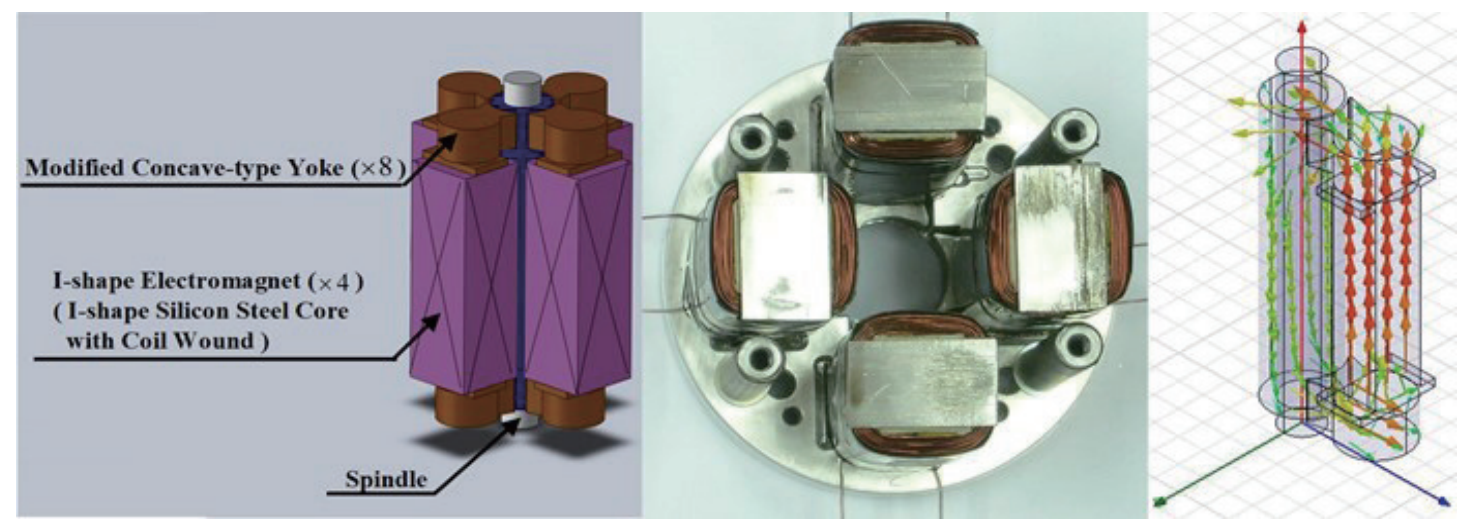

Fig. 3. (Color online) AMB model employed in this study. ${ }^{(19)}$ 


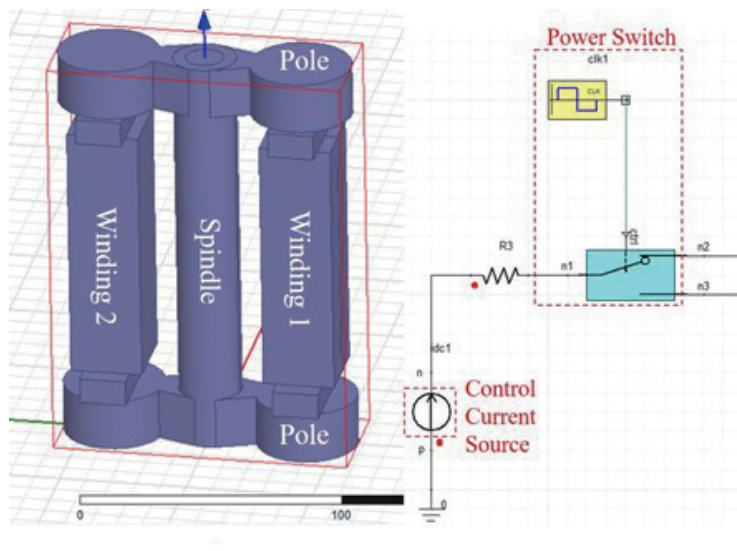

(a)

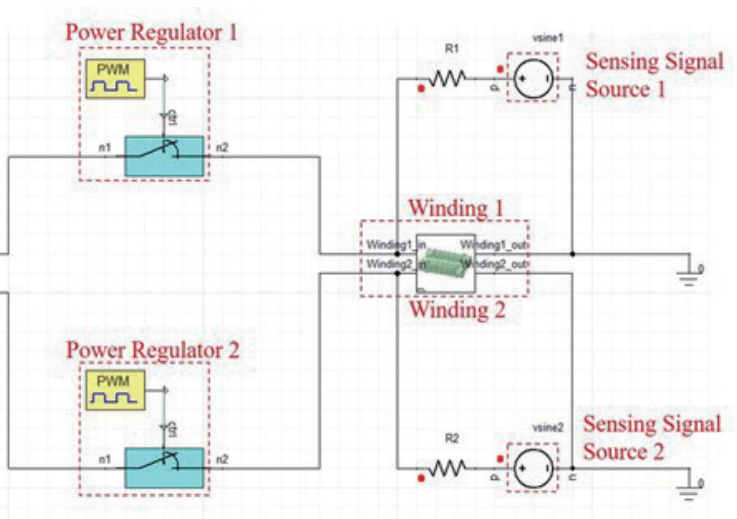

(b)

Fig. 4. (Color online) Simulation setup: (a) AMB model and (b) electrical supplies.

Table 1

Parameters of AMB operation in numerical simulations.

\begin{tabular}{lc}
\hline Parameter & Value \\
\hline Coil turns of a single electromagnet & 1200 turns \\
Electrical resistance of a single electromagnet (coil) & $10.4 \Omega$ \\
Nominal air gap between spindle and pole & $1 \mathrm{~mm}$ \\
Control current & $3 \mathrm{~A}$ \\
Time period of a single case analysis & $0.1 \mathrm{~s}$ \\
Waveform of sensing signal & Sine wave \\
Spindle position deviation & Defined in Table 2 \\
Frequency of sensing signal & Defined in Table 2 \\
\hline
\end{tabular}

power of the AMB operation, and the action of the power switch is determined according to the moving direction of the spindle. Power regulators are utilized to adjust the current strength supplied to the coils. Sensing signals are assumed to be identical in this work. The simulation parameters are listed in Table 1. The control current is supplied to the winding when the nearby air gap is larger than the nominal air gap. For example, when the spindle is moving toward winding 1, the control current is applied to winding 2 to pull the spindle back. In total, 20 cases are considered and the corresponding parameters are listed in Table 2. Two different sensing signal peaks are used to evaluate the interaction of the control command with the sensing signal. Five sensing frequencies and two different spindle displacements are adopted to compare the HF sensing performance.

\section{Simulation Results and Discussion}

The simulation results for groups A to D (see Table 2) are shown in Figs. 5 and 6. Four items are discussed: (1) the discriminating ability of the spindle displacement, (2) the frequency ranges of the sensing signal, (3) the influence of the control command on the sensing signal, and (4) the detection speed of the spindle displacement. From Figs. 5 and 6, an overlap of 
Table 2

Parameters of HF injection analyses.

\begin{tabular}{|c|c|c|c|c|}
\hline Group & No. & Sensing signal frequency & Peak voltage of sensing signal & Spindle position deviation \\
\hline \multirow{5}{*}{ A } & A1 & $1 \mathrm{kHz}$ & \multirow{5}{*}{$\begin{array}{c}3 \mathrm{~V} \\
(9.6 \% \text { of control voltage) }\end{array}$} & \multirow{5}{*}{$\begin{array}{c}\text { Spindle displacement of } 0.5 \mathrm{~mm} \\
\text { toward winding } 1 \\
\text { (air gaps on both sides of } \\
\text { spindle are } 0.5 \text { and } 1.5 \mathrm{~mm} \text { ) }\end{array}$} \\
\hline & A2 & $3 \mathrm{kHz}$ & & \\
\hline & A3 & $5 \mathrm{kHz}$ & & \\
\hline & A4 & $500 \mathrm{~Hz}$ & & \\
\hline & A5 & $100 \mathrm{~Hz}$ & & \\
\hline \multirow{5}{*}{ B } & B1 & $1 \mathrm{kHz}$ & \multirow{5}{*}{$\begin{array}{c}3 \mathrm{~V} \\
(9.6 \% \text { of control voltage })\end{array}$} & \multirow{5}{*}{$\begin{array}{c}\text { Spindle displacement of } 0.9 \mathrm{~mm} \\
\text { toward winding } 1 \\
\text { (air gaps on both sides of } \\
\text { spindle are } 0.1 \text { and } 1.9 \mathrm{~mm} \text { ) }\end{array}$} \\
\hline & B2 & $3 \mathrm{kHz}$ & & \\
\hline & B3 & $5 \mathrm{kHz}$ & & \\
\hline & B4 & $500 \mathrm{~Hz}$ & & \\
\hline & B5 & $100 \mathrm{~Hz}$ & & \\
\hline \multirow{5}{*}{$\mathrm{C}$} & $\mathrm{C} 1$ & $1 \mathrm{kHz}$ & & \multirow{5}{*}{$\begin{array}{c}\text { Spindle displacement of } 0.5 \mathrm{~mm} \\
\text { toward winding } 1 \\
\text { (air gaps on both sides of } \\
\text { spindle are } 0.5 \text { and } 1.5 \mathrm{~mm} \text { ) }\end{array}$} \\
\hline & $\mathrm{C} 2$ & $3 \mathrm{kHz}$ & & \\
\hline & $\mathrm{C} 3$ & $5 \mathrm{kHz}$ & $1 \mathrm{~V}, \mathrm{u}=\mathrm{x}$ & \\
\hline & $\mathrm{C} 4$ & $500 \mathrm{~Hz}$ & (3.2\% of control voltage) & \\
\hline & $\mathrm{C} 5$ & $100 \mathrm{~Hz}$ & & \\
\hline \multirow{5}{*}{$\mathrm{D}$} & D1 & $1 \mathrm{kHz}$ & \multirow{5}{*}{$\begin{array}{c}1 \mathrm{~V} \\
\text { (3.2\% of control voltage) }\end{array}$} & \multirow{5}{*}{$\begin{array}{c}\text { Spindle displacement of } 0.9 \mathrm{~mm} \\
\text { toward winding } 1 \\
\text { (air gaps on both sides of } \\
\text { spindle are } 0.1 \text { and } 1.9 \mathrm{~mm} \text { ) }\end{array}$} \\
\hline & $\mathrm{D} 2$ & $3 \mathrm{kHz}$ & & \\
\hline & D3 & $5 \mathrm{kHz}$ & & \\
\hline & D4 & $500 \mathrm{~Hz}$ & & \\
\hline & D5 & $100 \mathrm{~Hz}$ & & \\
\hline
\end{tabular}

induced voltages is observed in each result. Since the control current and the sensing signal are injected into winding 2 at the same time, at the initial stage, the induced voltage of winding 2 is higher than that of winding 1 . That is, the amplitude difference of the induced voltages during the fully overlapped segment corresponds to the spindle displacement. The discriminating ability of the spindle displacement is therefore confirmed. The second item is relevant to the signal frequency ranges in which the sensing performance is satisfactory. According to the case studies, the results for frequencies of $1 \mathrm{kHz}, 500 \mathrm{~Hz}$, and $100 \mathrm{~Hz}$ are potential options for spindle displacement detection owing to the regularity of the fully overlapped segments. The performance of the signal frequency from 1 to $3 \mathrm{kHz}$ has to be further addressed. The third item is regarding the strength ratio of the sensing signal to the control command. The main influence of the control command on the sensing signal can be observed at the initial stage in Figs. 5 and 6. Since the peak of the HF sensing signal is required to be as low as possible to maintain the control performance of the AMB, the strength of the sensing signal should be determined by sensing performance indexes such as the precision and speed of detection. The last item is one of the sensing performance indexes. The length difference of air gaps relative to windings 1 and 2 corresponds to the amplitude difference of the induced voltages during the fully overlapped segment. According to the results under a sensing frequency of $1 \mathrm{kHz}$, the times required to achieve the full overlap of induced voltages by sensing signal peaks of 1 and $3 \mathrm{~V}$ are about 0.07 and $0.06 \mathrm{~s}$, respectively. In addition, the detection time will increase with decreasing sensing frequency. As a result, the strength and frequency of the sensing signal have to be accurately evaluated to obtain a suitable balance between control and sensing performance. 


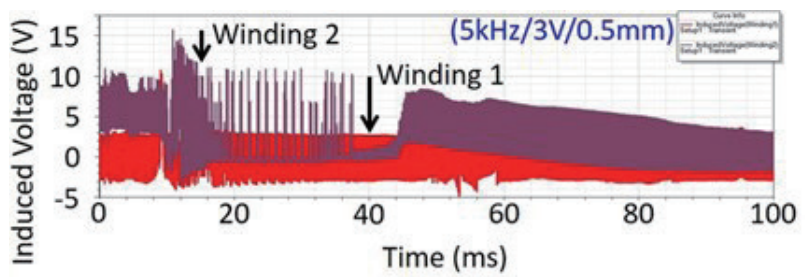

(a1)

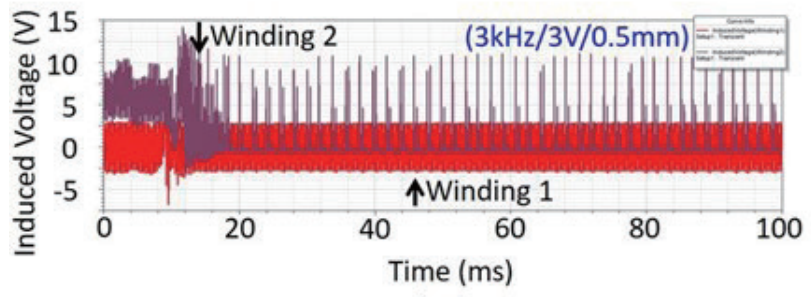

(a2)

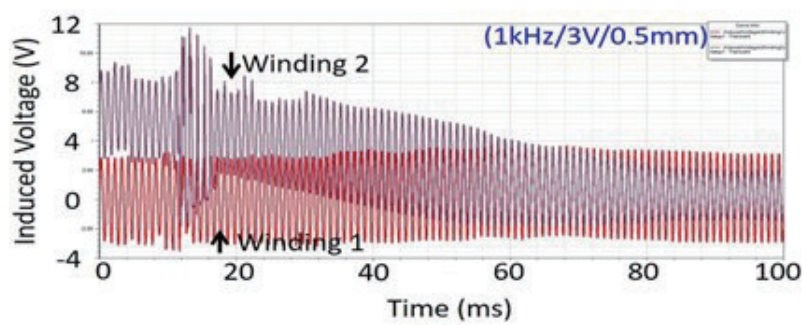

(a)

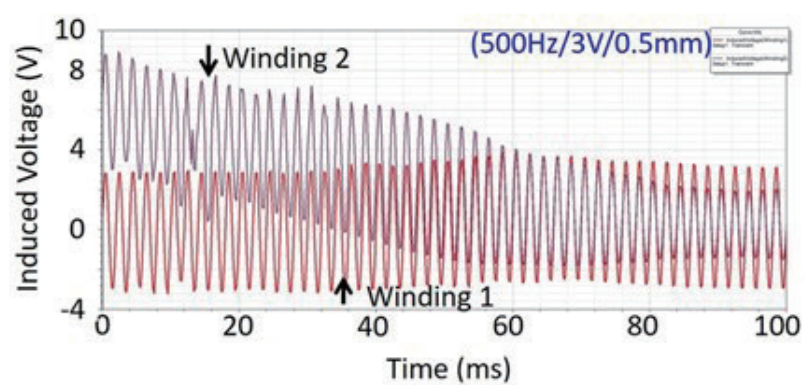

(a4)

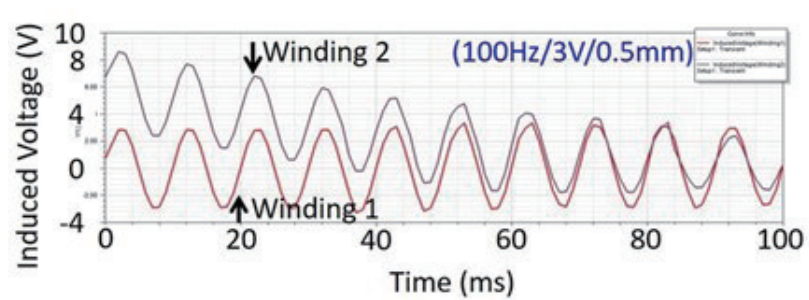

(a5)

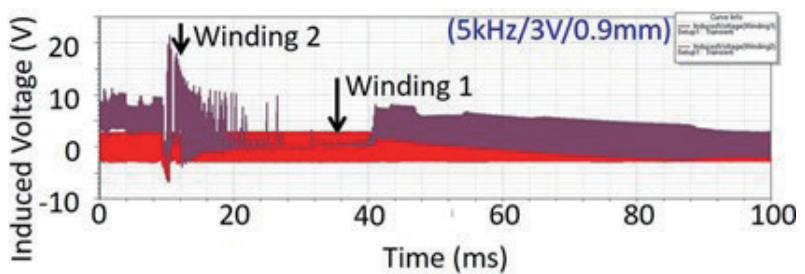

(b1)

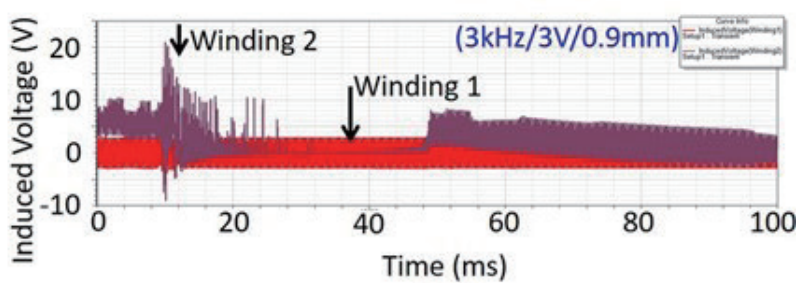

(b2)

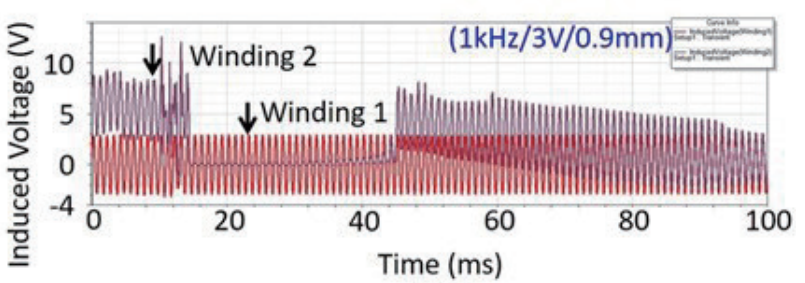

(b3)

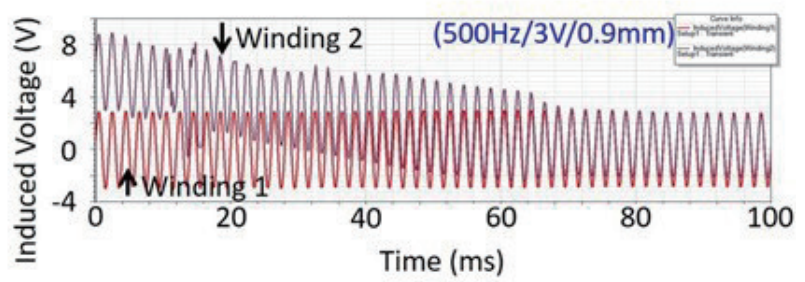

(b4)

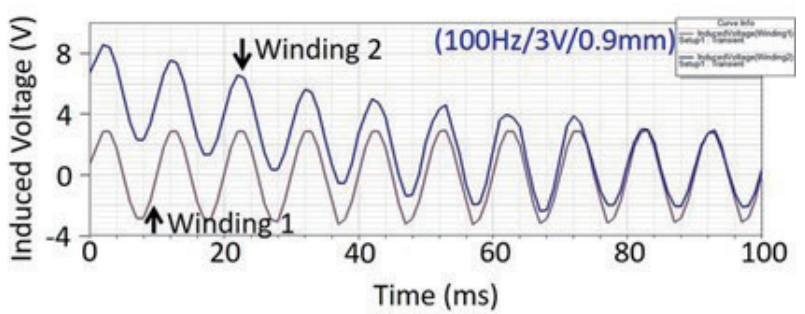

(b5)

Fig. 5. (Color online) Simulation results for (a1-a5) group A and (b1-b5) group B. 


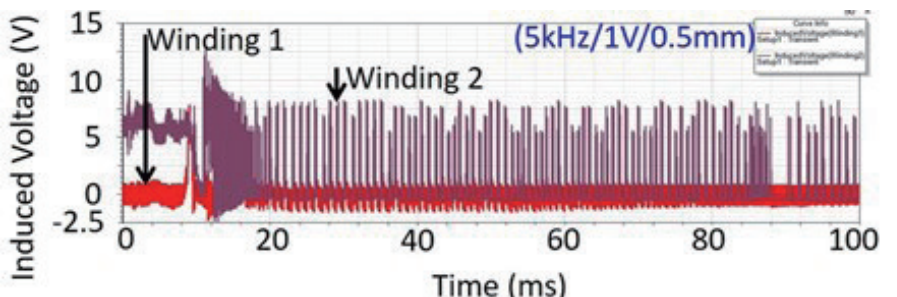

(c1)

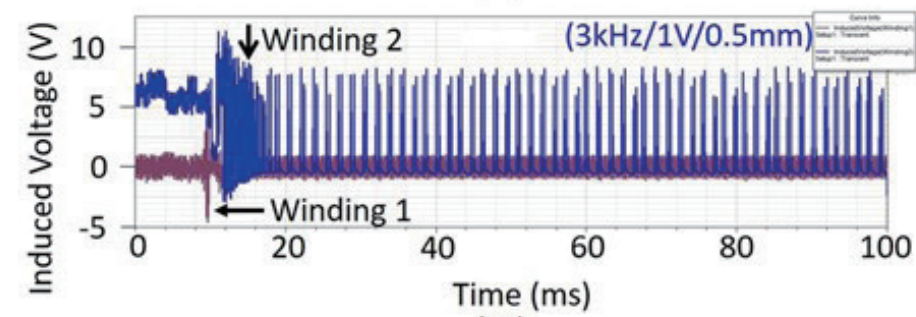

(c2)

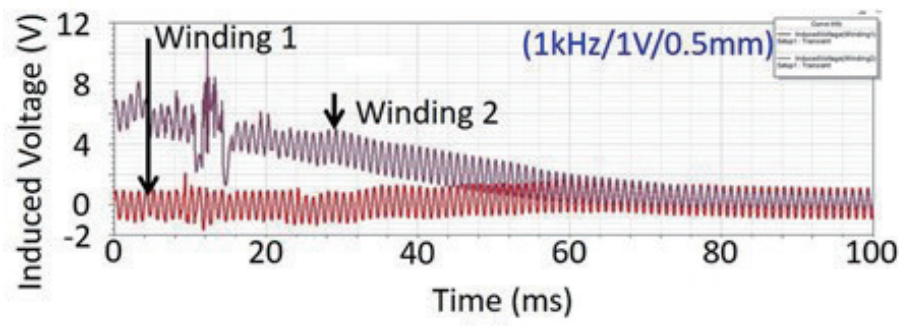

(c3)

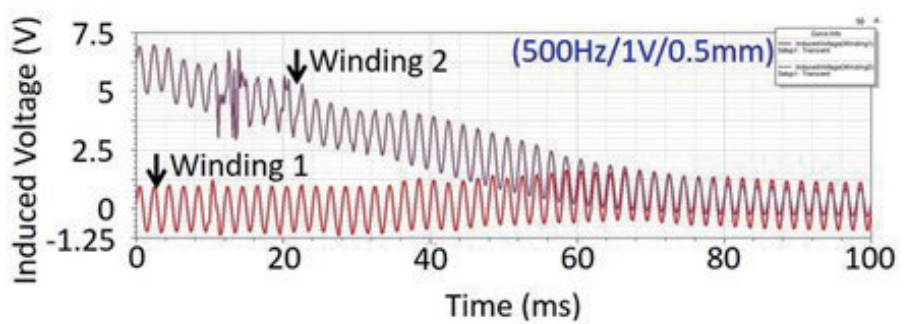

(c4)

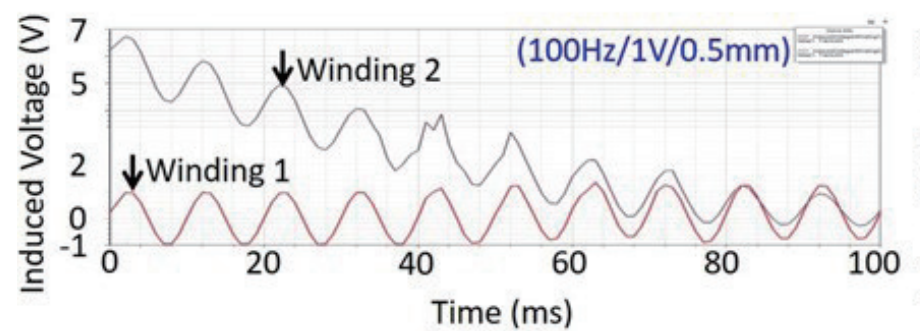

(c5)

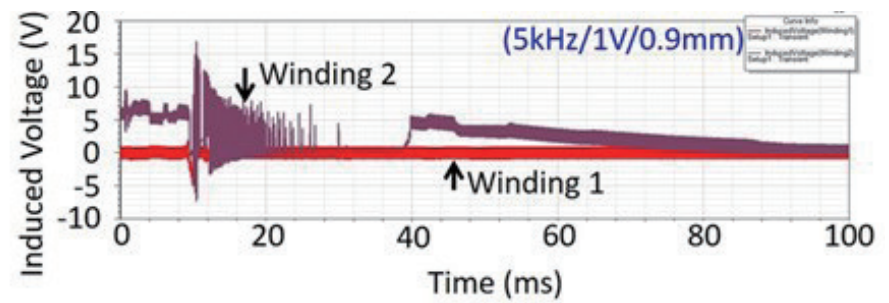

(d1)

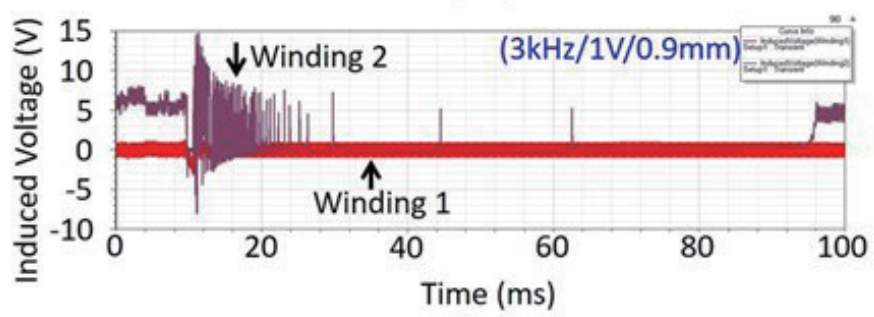

(d2)

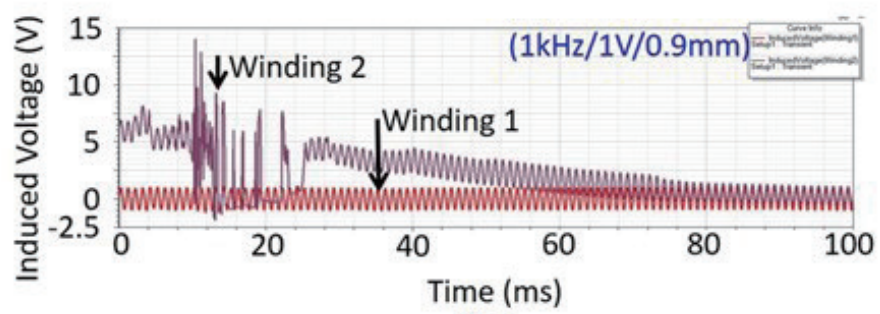

(d3)

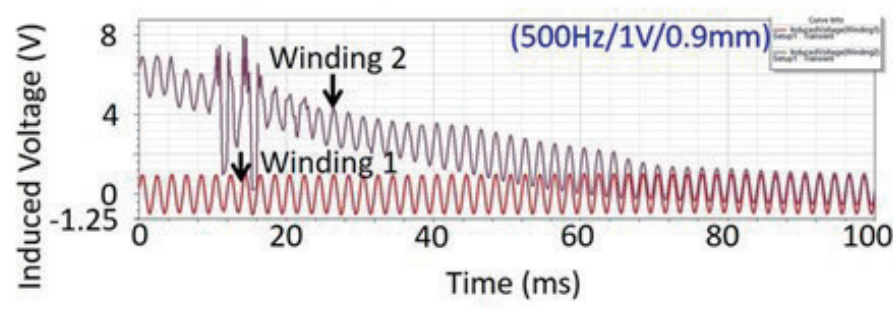

(d4)

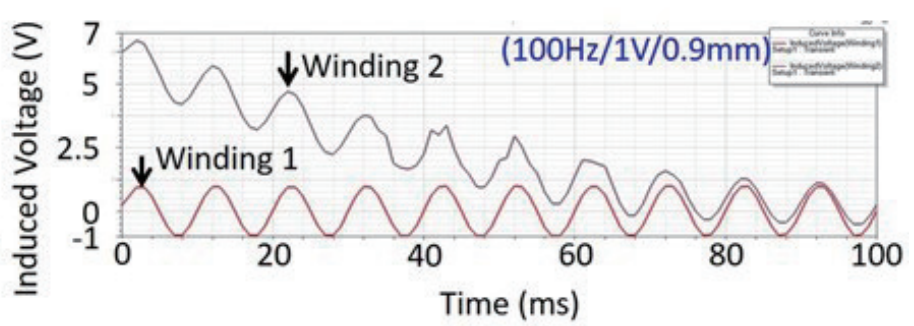

(d5)

Fig. 6. (Color online) Simulation results for (cl-c5) group C and (d1-d5) group D. 


\section{Conclusions}

A sensorless method of $\mathrm{HF}$ injection for a maglev rotor was discussed in this work. Owing to the complexity of electromechanical and electromagnetic dynamics, a simplified numerical analysis procedure was introduced to replace the derivation of mathematical models. A 3D model of the spindle and electromagnets, and the external circuit were loaded into an FEA platform to reduce analysis errors. Four indexes of the HF injection method were addressed: (1) the discriminating ability of the spindle displacement, (2) the frequency ranges of the sensing signal, (3) the influence of the control command on the sensing signal, and (4) the detection speed of the spindle displacement. On the basis of the simulation results, the performance is satisfactory for a sensing frequency of $1 \mathrm{kHz}$. For general purposes, the frequency range from $500 \mathrm{~Hz}$ to $1 \mathrm{kHz}$ may be satisfactory for the rotor displacement measurement. However, the detection speed is coupled with the signal peak (strength) and the sensing frequency. The parameters of the sensing signal have to be accurately determined to fulfill the performance requirements of $\mathrm{AMB}$ applications.

\section{Acknowledgments}

This work was supported by the Ministry of Science and Technology, Taiwan, under Grant No. MOST 108-2221-E-153-011.

\section{References}

1 S. C. Mukhopadhyay: 1st Int. Conf. Sensing Technology (Massey University, 2005) 425.

2 W. Gruber, M. Pichler, M. Rothbock, and W. Amrhein: 7th Int. Conf. Sensing Technology (Massey University, 2013) 591. https://doi.org/10.1109/ICSensT.2013.6727721

3 N. Morse, R. Smith, B. Paden, and J. Antaki: Proc. IEEE 37th Decision and Control Conf. (IEEE, 1998) 2599. https://doi.org/10.1109/CDC.1998.757843

4 T. Mizuno, K. Araki, and H. Bleuler: IEEE Trans. Control Syst. Technol. 4 (1996) 572. https://doi. org $/ 10.1109 / 87.531923$

5 E. H. Maslen, D. T. Montie, and T. Iwasaki: J. Dyn. Syst. Meas. Contr. 128 (2005) 197. https://doi. org/10.1115/1.2192820

6 J. Okada and K. N. Matsuda: Proc. 3rd Int. Symp. Magnetic Bearings (LCM, 1992) 176.

7 M. D. Noh: Ph.D. Dissertation (University of Virginia, 1996).

8 T. Yoshida, Y. Kuroba, K. Ohniwa, and M. Osamu: Eur. Power Electron. Drives 15 (2005) 19.

9 Y. Kato, T. Yoshida, and K. Ohniwa: Electr. Eng. Jpn. 165 (2008) 69. https://doi.org/10.1005/eej.20616

10 M. Tang, C.-S. Zhu, and J. Yu: Front. Inform. Technol. Electron. 14 (2013) 600. https://doi.org/10.1631/jzus. C1300023

11 A. C. Niemann, G. van Schoor, and C. P. du Rand: Sensors 13 (2013) 12149. https://doi.org/10.3390/s130912149

12 E. O. Ranft, G. van Schoor, and C. P. du Rand: Sens. Actuators, A 172 (2011) 410. https://doi.org/10.1016/ j.sna.2011.09.037

13 J. Yu and C. S. Zhu: IEEE Trans. Ind. Electron. 65 (2018) 6382. https://doi.org/10.1109/TIE.2017.2784340

14 X. Hu, X. Fang, R. Wang, and D. Tan: Sensors 20 (2020) 3497. https://doi.org/10.3390/s20123497

15 Y. H. Park, D. C. Han, D. Y. Jang, I. H. Park, and H. J. Ahn: J. Mech. Sci. Technol. 22 (2008) 1757. https://doi. org/10.1007/s12206-008-0608-1

16 G.-L. Wang, R.-F. Yang, Y. Yu, and Z. Xu: Electr. Mach. Control 14 (2010) 56.

17 S. Bolognani, S. Calligaro, R. Petrella, and M. Tursini: IEEE Trans. Ind. Appl. 47 (2011) 96. https://doi. org/10.1109/TIA.2010.2090317

18 W. Ji, G. Shi, B. Xu, and J. Xu: Adv. Mech. Eng. 9 (2017) 1. https://doi.org/10.1177/1687814017746244

19 N.-C. Tsai and R.-M. Lee: Int. J. Adv. Manuf. Technol. 53 (2011) 93. https://doi.org/10.1007/s00170-010-2830-0 